\title{
The Instability of Convection of Magma in the Chamber, Triggering Eruption in Volcanoes
}

\author{
Dr.(Prof.) V.C.A. Nair* \\ Educational Physicist, Distinguished Alumnus, Chancellor-Designated Resource Person \\ in the area of Physics of Shri J. J. T University, Jhunjhunu, Rajasthan-333001, India. \\ Research Scholar registered for the Degree of Doctor of Science (D.Sc) \\ at Madurai Kamaraj University, Madurai-625 021, Tamil Nadu, India. \\ *nairvca39@gmail.com
}

\begin{abstract}
The Paper begins with a brief account of the Pacific Ring of Fire and the location of Volcanoes in the Earth. The Magma Chamber and introduction to convection of Magma in the chamber are given vividly in a self-styled manner. The Rayleigh number is arrived at by making use of an extensive theory based on Navier-Stoke's equation of Fluid Mechanics. Graphical study of various critical Rayleigh numbers for the corresponding wave numbers. The instability of convection and the magma turbulence in the chamber leading to magma fragmentation and ultimately eruption. The Rayleigh number for magma in the chamber has been worked out. The Paper ends with a Conclusion.
\end{abstract}

Keywords: Convection, Convective vigor, Critical Rayleigh number, Eruption, Fluid Mechanics, Instability of convection, Magma, Magma Chamber, Magma Fragmentation, Magma Turbulence, Magma Viscosity, Minimum Rayleigh number, Pacific Ring of Fire, Rayleigh-Benard Convection, Rayleigh number, Rayleigh number for Magma in the Chamber, Volcano, Volcano Explosive Index

\section{REVIEW OF LITERATURE}

\section{INTRODUCTION}

1.The Volcanoes: USGS [14] There are about 1,500 potentially active volcanoes worldwide, apart from the continuous belts of volcanoes on the ocean floor at spreading centers like the Mid-Atlantic Ridge. About 500 of those 1,500 volcanoes have erupted in historical times. Many of those are located along the Pacific Rim in what is known as the "Ring of Fire."(Fig.1) BBC[1] In the United States, volcanoes in the Cascade Range and Alaska (Aleutian volcanic chain) are part of the Ring, while Hawaiian volcanoes form over a 'hot spot' near the center of the Ring. There are 169 potentially active volcanoes in the United States.

Each volcano is associated with at least one magma chamber even though some are associated with more than one. These magma chambers are potentially heat sources within the Earth below all volcanoes and remain in thermodynamic equilibrium

1.1 The Ring of Fire: According to Matt Rosenberg [6] the Ring of Fire is a 25,000 mile (40,000 km) horseshoe-shaped area of intense volcanic and seismic (earthquake) activity that follows the edges of the Pacific Ocean. Receiving its fiery name from the 452 dormant and active volcanoes that lie within it, the Ring of Fire includes $75 \%$ of the world's active volcanoes and is also responsible for $90 \%$ of the world's earthquakes. It is an arc of mountains, volcanoes, and oceanic trenches that stretch from New Zealand northward along the eastern edge of Asia, then east across the Aleutian Islands of Alaska, and then south along the western coasts of North and South America. 


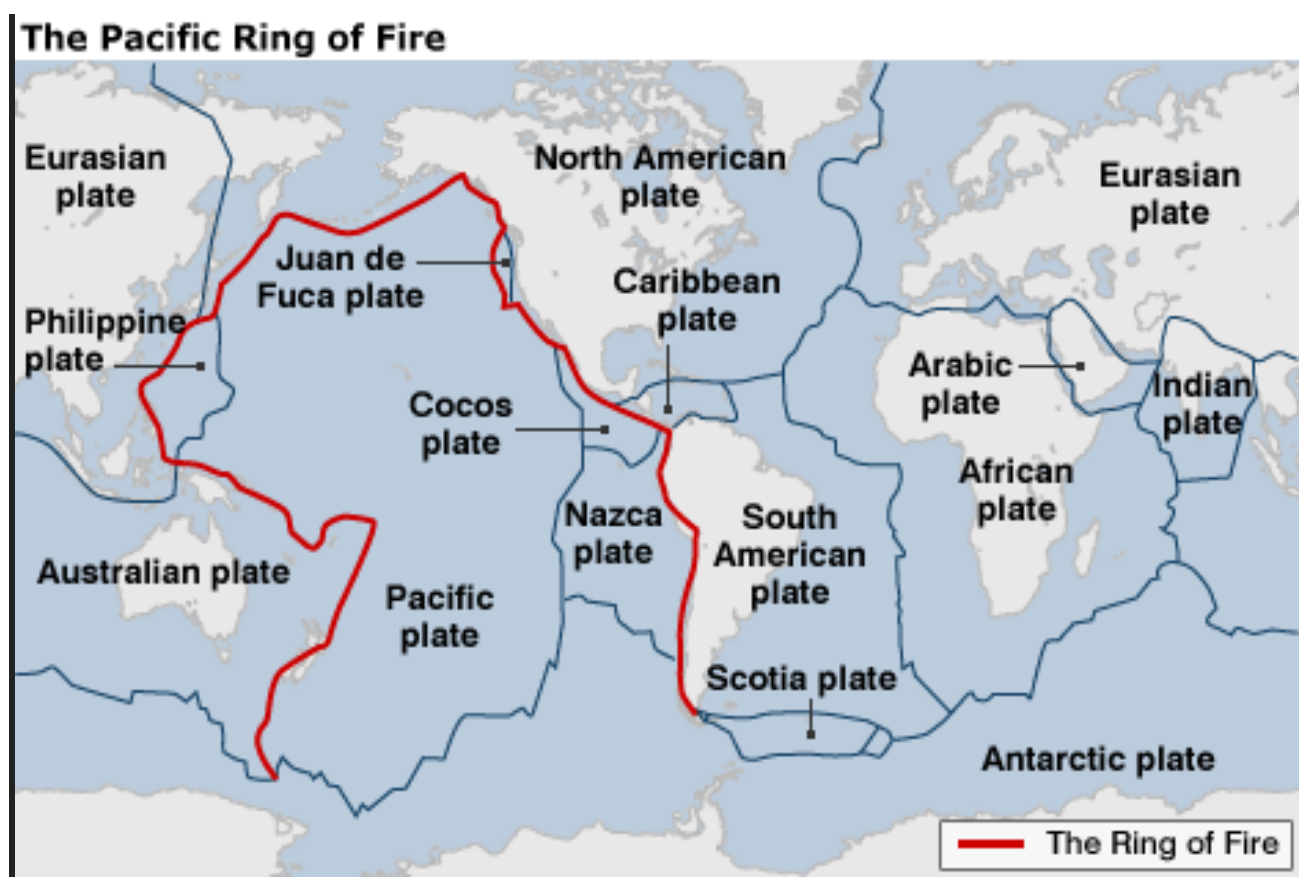

Fig.1 The Ring of Fire [1]

\section{THE MAGMA CHAMBER}

Nair V.C.A [8 Fig.1, p.2], author of this Paper has given a brief account of the Magma Chamber (Fig.2). gives the structural details from the point of view of location of Magma Chamber inside the Earth. The dimensions given vary from author to author. Physics, so is Geophysics, requires lot of imagination. You may look at an eruption of a volcano which has taught many things inside the Earth even though one cannot look at a magma chamber like site seeing. The values given are approximate. Coming to the size of a magma chamber, I have mentioned in one of my other Research Papers that the size of the magma chamber of a volcano of VEI 8 is almost equal to the size of the entire San Francisco Bay from Sacramento to San Jose in the California State of US. To compare with any place in India near Mumbai, the size can be taken as the area covering either Palghar or Thane districts of Maharashtra in India.

In the Figures drawn, the size of the magma chamber is shown elliptical even though its exact shape and size is just not known. Earth is a planet the internal structures of which are very complicated. There is enough freedom to study in detail about things which are found on the surface of the Earth such as the sea, rivers, the mountains, the atmosphere or clouds, but when it comes to the magma chamber, the tectonic plates or the configurations of the outer core or inner core, there has to be more imagination than realization. Many times, Mathematics which is the language of Physics helps in more realization and what the researcher decides is final. Regarding the shape and size of a magma chamber there is no counter question. I have drawn it elliptical. It can be circular, square or rectangular. Elliptical is near to rectangular or the square is near to circle. The reader has to imagine a 3-dimensional figure such as a parallelepiped for rectangle and sphere for a cube.

At equilibrium states, the magma in the chamber is a well set thermodynamic system maintaining steady difference of temperature due to the usual convection. A Steady convection exists as the magma at lower part being near the upper part of the mantle is at a high temperature $\mathrm{T}_{1}$ (Fig.3) and hence of low density. The low density magma rises above meet with the layers of crust and get cooled. The cooled magma with a slightly low temperature $T_{2}$ becomes heavier and comes down and again becomes hot and moves up as $\left(\mathrm{T}_{1}>\right.$ $\mathrm{T}_{2}$ ). This is a normal and steady convection (Fig.3) and is stable existing in all magma containers including the mantle which, in fact, is considered as an ocean of magma. L is the width or height of the magma Chamber that is the distance between the hot and cold face or the distance between the outlet to the volcano and the inlet from the mantle 


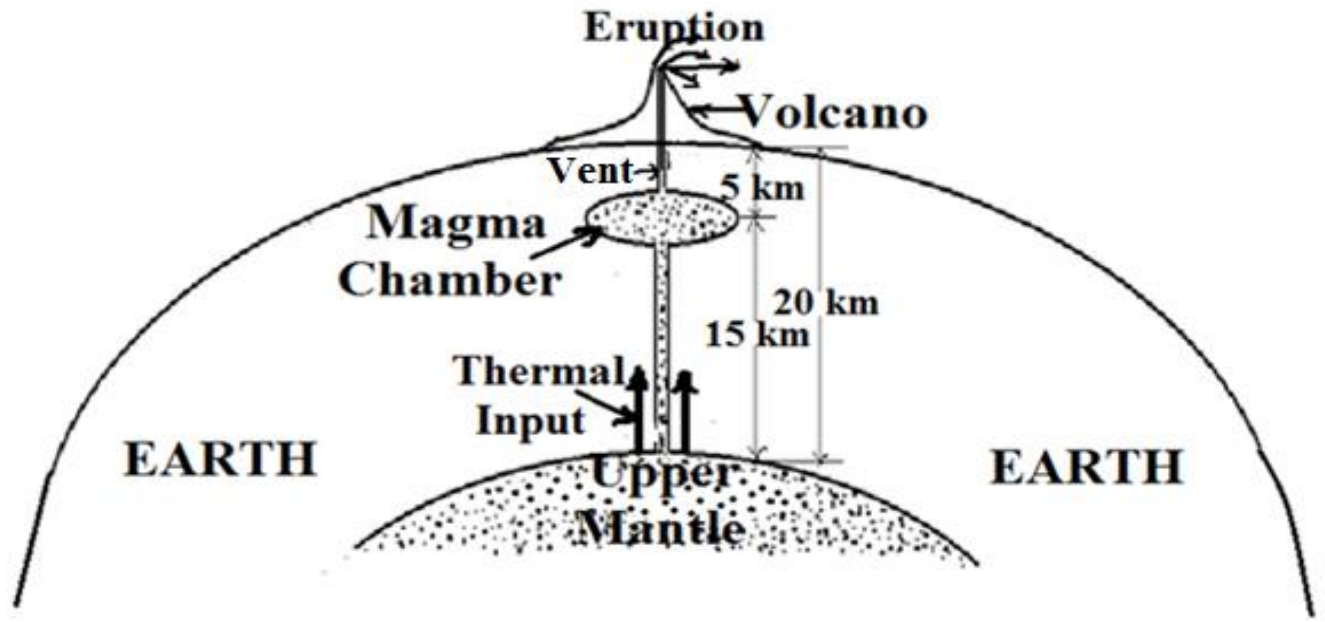

\section{A N T L E}

Fig.2 Location of Magma Chamber inside the Earth (Illustration drawn by Author: (C) IARJSET)

\section{MAGMA CONVECTION}

3.1 Historical: Nair V.C.A [9] has dealt with at length the convection of Earth's mantle the physical processes of which are almost the same as those of the magma in the chamber. The theory of 'Convection' dates back to the $19^{\text {th }}$ century. The phenomenon of convection was first recognized by Count Rumford (1870) and James Thomson (1882) brother of Lord Kelvin. Exactly at the beginning of the $20^{\text {th }}$ century Henry Benard (1900) noticed that as one surface of the liquid is open to the atmosphere, effect of surface tension has to be considered in addition to thermal convection. The results obtained were in agreement with what was shown later by Lord Rayleigh in 1916. Lord Rayleigh was the first to consider a linear problem of the onset of thermal convection in a horizontal layer. It was Arthur Holmes in 1931 who

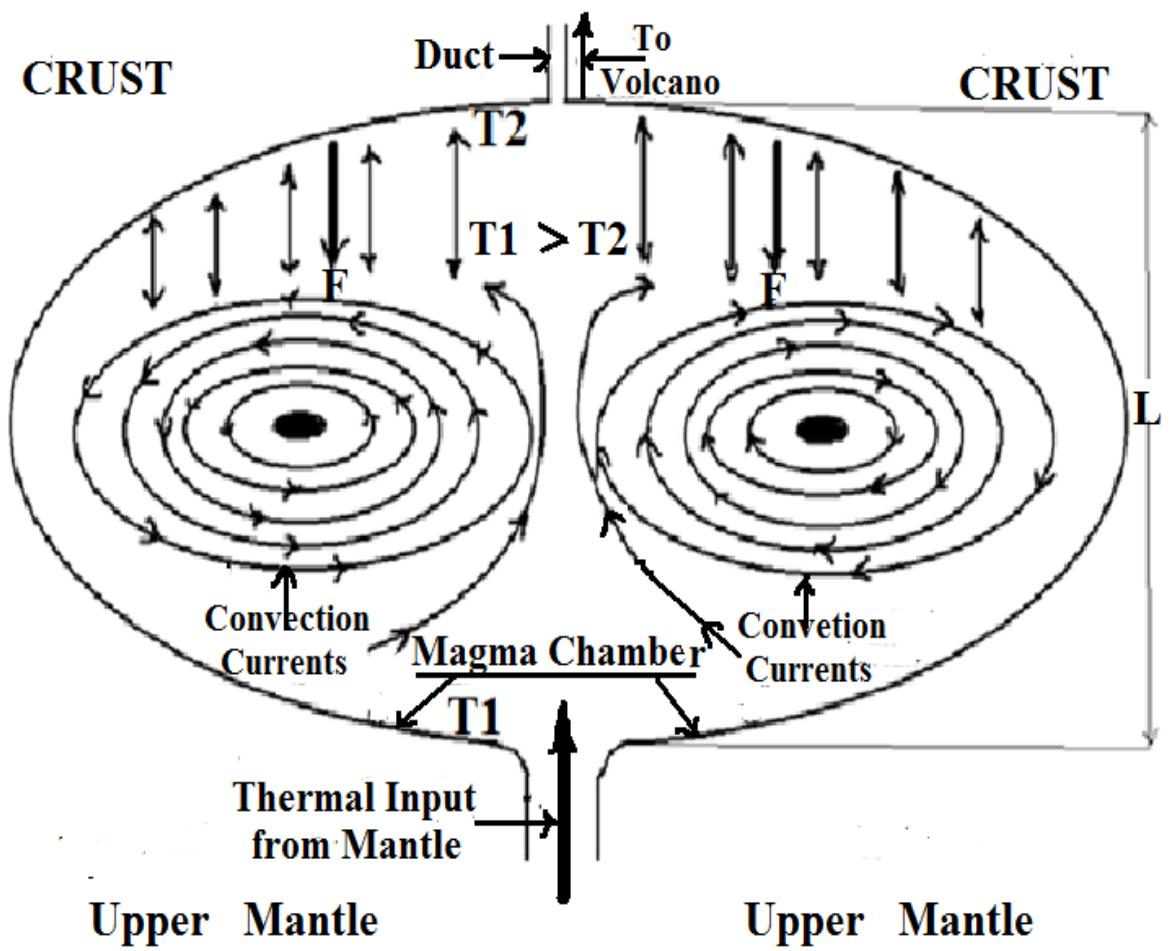

Fig.3 Illustration of Magma Convection inside the Magma Chamber (Drawn by Author: () IARJSET) 


\section{International Advanced Research Journal in Science, Engineering and Technology}

Vol. 6, Issue 9, September 2019

Correctl identified convection as the ultimate driving force for continental motion. A more comprehensive analysis of the problem was given by Pellew and Southwell in the year 1940. Later in the year $1961 \mathrm{~S}$. Chandrasekhar considered the effect of magnetic field and rotation of the Earth in a monograph. As the extensive pioneering work was done by both Lord Rayleigh (Fig.6) and Henri Benard (Fig.7) the convection what we deal with is legitimately called "Rayleigh-Benard Convection" or Benard-Rayleigh convection or simply Rayleigh convection.

The magma in the chamber which is at a temperature of over $1000^{\circ} \mathrm{C}$ is more a fluid than a solid For a generalized mathematical treatment given below, it is legitimate to use the word, 'Gas' for the material of the molten fluid under consideration thereby falling in line with the usual treatment found elsewhere in which terms, 'Gas' and 'Fluid' are synonymously used. To see to what extent a molten magma can vaporize and behave as a gas, readers may refer Nair .V.C.A [8].

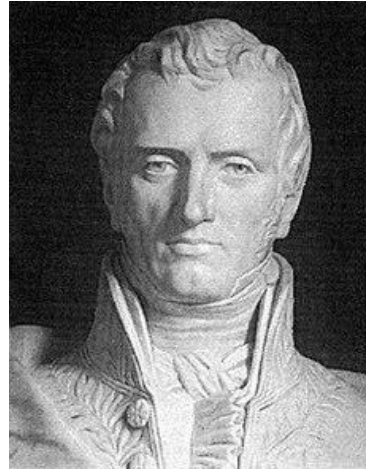

Fig.4 C L M H Navier $(1785-1836)$

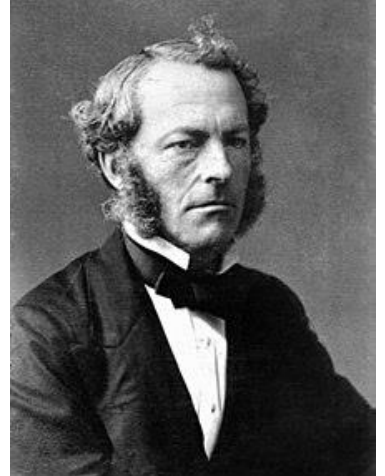

Fig.5 Sir Stokes (1819-1903)

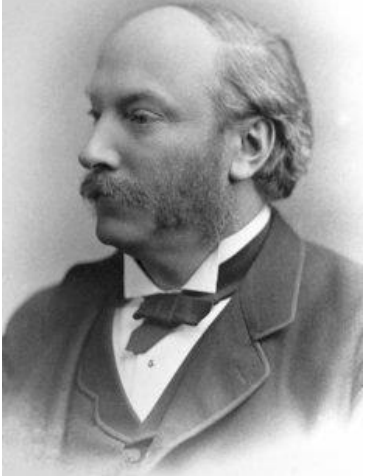

Fig.6 Lord Rayleigh $(1842-1919)$

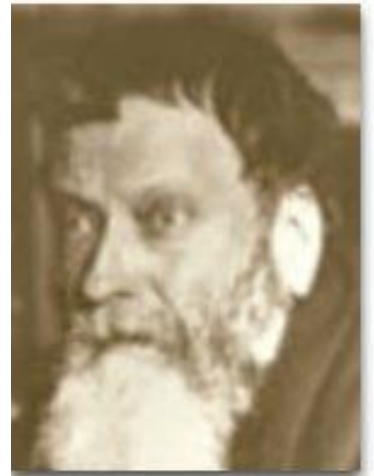

Fig.7 Henri Benard (1874-1939)

3.2 Theory based on Fluid Mechanics: We follow the theory given by B.M. Smirnov [11] and start with an equation first developed by French engineer, C.LM.H. Navier (1823) (Fig.4) and Irish scientist, George. G. Stokes (1845) (Fig. 5) known as the Navier -Stoke's equation:

$$
\frac{\partial \mathbf{v}}{\partial \mathrm{t}}+(\mathbf{v} \nabla) \mathbf{v}=-\frac{\operatorname{grad} p}{\rho}+\frac{\eta}{\rho} \nabla^{2} \mathbf{v}+\frac{\eta}{3 \rho} \operatorname{grad} \operatorname{div} \mathbf{v}+\frac{\mathbf{F}}{\mathrm{M}}
$$

along with the equation of continuity:

$$
\frac{\partial \mathrm{N}}{\partial \mathrm{t}}+\operatorname{div}(\mathrm{N} \mathbf{v})=0
$$

and the equation of heat transport;

$$
\frac{\partial \mathrm{T}}{\partial \mathrm{t}}+\mathbf{v} \operatorname{grad} \mathrm{T}=\frac{\chi}{\mathrm{Nc}_{\mathrm{v}}} \nabla^{2} \mathrm{~T}
$$

where

$\mathrm{N}$ is the number density of gas particles;

$\mathrm{p}$, the gas pressure;

$\mathrm{T}$, the temperature;

$\mathrm{c}_{\mathrm{V}}$ the specific heat per molecule;

$\eta$, the viscosity;

$\chi$, the thermal conductivity;

$\mathrm{M}$, the mass of a gas molecule;

$\mathbf{F}$, the force acting on one molecule;

$\mathbf{v}$, the mean velocity referred to as the drift velocity and

$\rho=\mathrm{MN}$ is the mass density.

When the temperature gradient is large in a gas which is in a field of external forces, there may appear a more effective mechanism of heat transport than thermal conduction and that is nothing but 'Convection'. This process consists in the movement of the warmer gas into the cooler regions such as the crust of the earth and the cooler gas into the hot regions such as the mantle of earth. 
Vol. 6, Issue 9, September 2019

We have to analyze the stability of gas at rest with the possibility of development of convection. Consider a gas at rest in which a temperature gradient is maintained in the field of external forces. The parameters of the gas are subjected to a small perturbation which is due to the slow motion of the gas and corresponds to convection. If this perturbation proves to be possible, convective instability can develop in such a gas. We have to find the conditions needed for the convective instability to occur so as to have convective heat transport.

The simplest problem can be studied by looking upon the so-called 'Rayleigh problem' of the weakly ionized plasma. The magma in the chamber has similar properties of the plasma just mentioned and lies between the crust and the upper mantle. The lower boundary of the crust and the upper boundary of the mantle can be taken as two infinite parallel walls and the hot fluid fills between them. The temperature of the lower wall is $T_{1}$, the temperature of the upper wall is $T_{2}$ with $T_{1}$ higher than $T_{2}$ (Fig.3). The force of the external field is directed downwards and perpendicular to the walls. Let $\mathrm{L}$ be the distance between the walls. We shall find out the conditions for convective instability.

Let us represent the parameters of the gas as sums of two terms: the first term is the parameter for the gas at rest and the second term is a small perturbation of the parameter due to the convective motion of the gas. The author, Nair V.C.A [8, p.3] has considered a number of possible perturbations. Thus, the gas density is $\mathrm{N}+\mathrm{N}^{\prime}$, the gas pressure is $\mathrm{p}_{0}+\mathrm{p}^{\prime}$, the gas temperature is $\mathrm{T}+\mathrm{T}^{\prime}$ and the gas velocity is $\mathbf{v}$, which is zero in the absence of convection. The perturbed quantities are shown with primes. Now, insert these parameters into the stationary equations of continuity (2), of the Navier-Stoke's equation (1) and of heat transport (3). The zero order approximation is,

$$
\begin{gathered}
\operatorname{grad} \mathrm{p}_{0}=-\mathbf{F N}, \\
\nabla^{2} \mathrm{~T}=0
\end{gathered}
$$

In the first small-parameter approximation, these equations yield

$$
\begin{aligned}
\operatorname{div} \mathbf{v} & =0, \\
-\frac{\operatorname{grad}\left(\mathrm{p}_{0}+\mathrm{p}^{\prime}\right)}{\left(\mathrm{N}+\mathrm{N}^{\prime}\right)}+\frac{\eta \nabla^{2} \mathrm{v}}{\left(\mathrm{N}+\mathrm{N}^{\prime}\right)}+\mathbf{F} & =0 \\
-\mathrm{v}_{\mathrm{z}}\left[\frac{\mathrm{T}_{1}-\mathrm{T}_{2}}{\mathrm{~L}}\right] & =\frac{\chi}{\mathrm{Nc}_{\mathrm{v}}} \nabla^{2} \mathrm{~T},
\end{aligned}
$$
to the walls.

The parameters of the above problem are used in the last equation. Here, the z-axis is perpendicular term is,

Transform the first term in the second equation of (4). Up to the first order of approximation, the

$$
\frac{\operatorname{grad}\left(\mathrm{p}_{0}+\mathrm{p}^{\prime}\right)}{\left(\mathrm{N}+\mathrm{N}^{\prime}\right)}=\frac{\operatorname{grad} \mathrm{p}_{0}}{\mathrm{~N}}+\frac{\operatorname{grad} \mathrm{p}^{\prime}}{\mathrm{N}}-\frac{\operatorname{grad} \mathrm{p}_{0}}{\mathrm{~N}}\left(\frac{\mathrm{N}^{\prime}}{\mathrm{N}}\right)=\mathbf{F}\left(\frac{\mathrm{N}-\mathrm{N}^{\prime}}{\mathrm{N}}\right)+\frac{\operatorname{grad} \mathrm{p}^{\prime}}{\mathrm{N}}
$$

According to the equation of state, $p=N T, N=\left(\frac{p}{T}\right)$ and hence we find that $\mathrm{N}^{\prime}=\left(\frac{\partial \mathrm{N}}{\partial \mathrm{T}}\right)_{\mathrm{p}} \mathrm{T}^{\prime}=-\mathrm{N}\left(\frac{\mathrm{T}^{\prime}}{\mathrm{T}}\right)$

Inserting this relation into the second equation of (4), we can write the system of equations (4) as

$$
\begin{aligned}
& \quad \text { Div } \mathbf{v}=0, \\
& \quad \frac{\operatorname{grad~p^{\prime }}}{\mathrm{N}}-\mathbf{F}\left(\frac{\mathrm{T}^{\prime}}{\mathrm{T}}\right)-\frac{\eta}{\mathrm{N}} \nabla^{2} \mathrm{v}=0 \\
& \mathrm{v}_{\mathrm{Z}}=\left[\frac{\chi \mathrm{L}}{\mathrm{N} \mathrm{c}_{\mathrm{v}}\left(\mathrm{T}_{2}-\mathrm{T}_{1}\right)}\right] \nabla^{2} \mathrm{~T}^{\prime}
\end{aligned}
$$

Let us reduce the system of equations (5) which connect the parameters of the gas, to an equation for one parameter. First, we apply to the second equation of (5) the operator 'div' and take into account the first equation of (5). We find that

$$
\frac{\partial^{2} \mathbf{p}^{\prime}}{\mathrm{N}}-\left(\frac{\mathbf{F}}{\mathrm{T}}\right) \frac{\partial \mathrm{T}^{\prime}}{\partial \mathrm{z}}=0
$$

As $\left(\mathrm{T}_{1}>\mathrm{T}_{2}\right),\left[\frac{\left(\mathrm{T}_{1}-\mathrm{T}_{2}\right)}{\mathrm{T}_{1}}\right]<<1$ and hence the undisturbed parameters of the gas do not vary much inside the volume being considered. We shall neglect their variation and assume that the unperturbed gas parameters are spatially constant. 


\section{International Advanced Research Journal in Science, Engineering and Technology}

Vol. 6, Issue 9, September 2019

Inserting $\mathrm{v}_{\mathrm{z}}$ from the third equation of (5) into the $\mathrm{z}^{\text {th }}$ component of the second equation and making use of the operator $\nabla^{2}$,

$$
\frac{1 \partial}{\mathrm{N} \partial \mathrm{z}}\left(\nabla^{2} \mathrm{p}^{\prime}\right)-\mathbf{F}\left(\frac{\nabla^{2} \mathrm{~T}^{\prime}}{\mathrm{T}}\right)+\left[\frac{\eta \chi \mathrm{L}}{\mathrm{N}^{2} \mathrm{c}_{\mathrm{V}}\left(\mathrm{T}_{2}-\mathrm{T}_{1}\right)}\right]\left(\nabla^{2}\right)^{3} \mathrm{~T}^{\prime}=0
$$

Combining this with equation (6) we get finally

$$
\left(\nabla^{2}\right)^{3} \mathrm{~T}^{\prime}=-\frac{\mathrm{R}}{\mathrm{L}^{4}}\left(\nabla^{2}-\frac{\partial^{2}}{\partial \mathrm{z}^{2}}\right) \mathrm{T}^{\prime}
$$

where the dimensionless combination of parameters

$\mathrm{R}$ is called as the Rayleigh Number and is a dimensionless quantity which can be brought to a standard form. Writing $\Delta \mathrm{T}$ for $\left(\mathrm{T}_{1}-\mathrm{T}_{2}\right)$ and for unit mass, $\rho=\mathrm{MN}=\mathrm{N}$ and the force $\mathbf{F}=\mathrm{g}$, the acceleration due to gravity, we can write $\mathrm{R}$ as

$$
\mathrm{R}=\left[\frac{\left.\Delta \mathrm{T} \mathrm{c}_{\mathrm{v}} \mathbf{g} \rho^{2} \mathrm{~L}^{3}\right)}{\eta \chi \mathrm{T}}\right]
$$

The reciprocal of temperature T appearing as a multiple in this equation is the volumetric expansion $\beta$ of the fluid which brings in the effect of buoyancy in free convection and for an ideal gas we can write $\beta=\frac{1}{\mathrm{~T}}$ where $\mathrm{T}$ is the absolute temperature of the gas* .

* It follows from elementary theories on 'Heat and Thermodynamics' that by definition $\beta$ is the rate of decrease of density with temperature per unit change of density leading to buoyancy. That is, $\beta=-\left[\frac{1}{\rho}\left(\frac{\partial \rho}{\partial \mathrm{T}}\right)_{\mathrm{P}}\right]$. Minus sign indicating decrease. Now, for an ideal gas, pressure $\mathrm{P}=\rho \mathrm{RT}$ where $\mathrm{T}$ is the absolute temperature or $\rho=\frac{\mathrm{P}}{\mathrm{RT}}$. Differentiating by keeping the pressure constant, $\left(\frac{d \rho}{\mathrm{dT}}\right)_{\mathrm{P}}=-\frac{\mathrm{P}}{\mathrm{RT}^{2}}=-\left(\frac{\rho \mathrm{RT}}{\mathrm{RT}^{2}}\right)=$ $\left(-\frac{\rho}{\mathrm{T}}\right)$ and finally,

$$
\beta=\left[-\left(\frac{1}{\rho}\right)\left(-\frac{\rho}{T}\right)\right]=\frac{1}{T}
$$

With this the Rayleigh number takes the standard form

$$
\mathrm{R}_{\mathrm{a}}=\left[\frac{\left(\beta \Delta \mathrm{T} \mathrm{c}_{\mathrm{v}} \mathbf{g} \rho^{2} \mathrm{~L}^{3}\right)}{\eta \chi}\right]
$$

The Rayleigh number $\mathrm{R}_{\mathrm{a}} @$ given by equation (9) is thus the ratio, buoyant force divided by the product of the viscous drag and the rate of heat diffusion. In the treatment of magma convection, $\Delta \mathrm{T}$ is the super adiabatic temperature across the shell of domain thickness $\mathrm{L}$ which is usually greater than $25 \mathrm{~km}$ in the case a magma chamber and $2500 \mathrm{~km}$ in the case of Mantle.

@ $\mathrm{R}_{\mathrm{a}}$, that is $\mathrm{R}$ with suffix a is a standard representation and is so denoted to honor the great physicist Lord Rayleigh (Fig.6) by taking the first two alphabets from his name.

\section{THE RAYLEIGH NUMBER}

4. Equation (9) shows that the Rayleigh number determines the possibility of development of convection.

For example, in the Rayleigh problem, the boundary conditions at the walls are $T^{\prime}=0, v_{z}=0$. Also the tangential forces, $\eta\left(\frac{\partial \mathbf{v}_{\mathbf{x}}}{\partial \mathrm{z}}\right)$ and $\left(\frac{\partial \mathbf{v}_{\mathrm{y}}}{\partial \mathrm{z}}\right)$ are zero at the walls. Differentiating the equation, $\operatorname{div} \mathbf{v}=0$ with respect to $\mathrm{z}$ and using the conditions for the tangential forces, we find that at the walls $\left(\frac{\partial^{2} \mathrm{v}_{\mathrm{z}}}{\partial \mathrm{z}^{2}}\right)=0$. Hence, we have the following boundary conditions.

$$
\mathrm{T}^{\prime}=0, \quad \mathrm{v}_{\mathrm{z}}=0 \quad \text { and }\left(\frac{\partial^{2} \mathrm{v}_{\mathrm{z}}}{\partial \mathrm{z}^{2}}\right)=0
$$




\section{International Advanced Research Journal in Science, Engineering and Technology}

Vol. 6, Issue 9, September 2019

Denote by $z=0$ the coordinate of the lower wall. The general solution of equation (7) with the boundary condition, $\mathrm{T}^{\prime}=0$ at $\mathrm{z}=0$ can be expressed as

$$
\mathrm{T}^{\prime}=\mathrm{C} \exp \left[\mathrm{i}\left(\mathrm{k}_{\mathrm{x}} \mathrm{x}+\mathrm{k}_{\mathrm{y}} \mathrm{y}\right)\right] \sin \mathrm{k}_{\mathrm{z}} \mathrm{z}
$$

The boundary condition, $T^{\prime}=0$ at $z=L$ yields $k_{z} L=\pi n$ where $n$ is an integer. Inserting the solution given by equation (10) into equation (7), we get

$$
\mathrm{R}_{\mathrm{a}}=\left[\frac{\left(\mathrm{k}^{2} \mathrm{~L}+\pi^{2} n^{2}\right)}{k^{2} \mathrm{~L}^{2}}\right]
$$

where $\mathrm{k}^{2}=\mathrm{k}_{\mathrm{x}}{ }^{2}+\mathrm{k}_{\mathrm{y}}^{2}$. The solution given by equation (10) satisfies all boundary conditions.

4.1 Critical Rayleigh Number: Lord Rayleigh showed that the critical wave numberk ${ }_{\mathrm{c}}$ for two stress-free boundaries is $\left(\frac{\pi}{\mathrm{L} \sqrt{2}}\right)$ With this and keeping $n=1$, we can get the value of critical Rayleigh number, $R_{c}$ from equation (11) as follows:

$$
\begin{gathered}
\mathrm{R}_{a c}=\frac{\left(\mathrm{k}_{\mathrm{c}}{ }^{2} \mathrm{~L}^{2}+\pi^{2} n^{2}\right)^{3}}{\mathrm{k}_{\mathrm{c}}{ }^{2} \mathrm{~L}^{2}} \\
=\frac{\left(\frac{\pi^{2}}{2}+\pi^{2}\right)^{3}}{\frac{\pi^{2}}{2}}=\frac{\left[\pi^{2}\left(1+\frac{1}{2}\right)\right]^{3}}{\frac{\pi^{2}}{2}}=\frac{2 \pi^{6}\left(\frac{3}{2}\right)^{3}}{\pi^{2}}=2 \pi^{4}\left(\frac{27}{8}\right)=\left(\frac{27}{4}\right) \pi^{4}=657.51 \approx 658 . \text { Thus, } 658 \text { is the minimum }
\end{gathered}
$$

Rayleigh number $\mathrm{R}_{\mathrm{a}(\mathrm{min})}$ required for convection. That is,

$$
\mathrm{R}_{\mathrm{a}(\text { min. })} \approx 658
$$

This is the minimum value of Rayleigh number required for readily induced and free convection. The magnitude of $R_{a(\min )}$ however varies according to the geometry of the problem, but in all cases it is the Rayleigh number that characterizes the possibility of convection. The critical Rayleigh number for different types of boundaries and for various critical wave number are given by Hans-Peter Bunge [4] and shown in Table No.1

Table No.1

\begin{tabular}{|l|c|c|}
\hline \multicolumn{1}{|c|}{ Type of Boundary } & Critical Wave number $\mathbf{k}_{\mathbf{c}}$ & Critical Rayleigh number $\mathbf{R}_{\mathbf{a c}}$ \\
\hline 2 Stress-free boundaries & $\frac{\pi}{\sqrt{2}}=2.221$ & $\frac{\mathbf{2 7}}{\mathbf{4}} \pi^{4}=657.51 \approx 658$ \\
\hline 2 Rigid boundaries & 3.117 & $1707.8 \approx 1708$ \\
\hline $\begin{array}{l}1 \quad \text { Rigid and } 1 \text { stress-free } \\
\text { boundaries }\end{array}$ & 2.682 & 1100.66 \\
\hline
\end{tabular}

A plot of Critical Wave number, $\mathrm{k}_{\mathrm{c}}$ versus the critical Rayleigh number $\mathrm{R}_{\mathrm{ac}}$ yields the graph shown in Fig.8. The fluid is unstable inside the curve which has a minimum with co-ordinates $R_{a(m i n)}=1708$ and $k_{c}$ = 3.117. Dr. Lennon O Naraigh [5] as a solution to some problem in Rayleigh-Benard Convection obtained the neutral curve similar to Fig. 8 and the same is shown in Fig.9

The value of the critical Rayleigh number according to linear stability theory is $R_{a c}=1708$ at wavenumber $\mathrm{k}_{\mathrm{c}}=3.117$. Beyond this value the fluid starts to move and forms the counter-rotating 2-D rolls, the cross-section of which is almost square. The cellular flow becomes considerably more complicated as Ra increases. The 2-D rolls break up in 3-D cells, which appear hexagonal in shape when viewed from above. With larger $\mathrm{R}_{\mathrm{a}}$ numbers, the cells multiply, becoming oscillatory and finally turbulent.

Jovanović, M. M., et.al .mentioned an approximation called Oberbeck-Boussinesq approximation is said to be valid according to which all fluid properties are considered constant except density, which is assumed to be a linear function of temperature: That is,

$$
\rho=\rho_{2}\left[1-\beta\left(T-T_{2}\right)\right]
$$

where $\rho_{2}$ is the fluid density at the upper plate near the crust and $\mathrm{T}=\left(\frac{\mathrm{T}_{1}+\mathrm{T}_{2}}{2}\right)$ is the mean fluid temperature between the walls of height $\mathrm{L}$ 


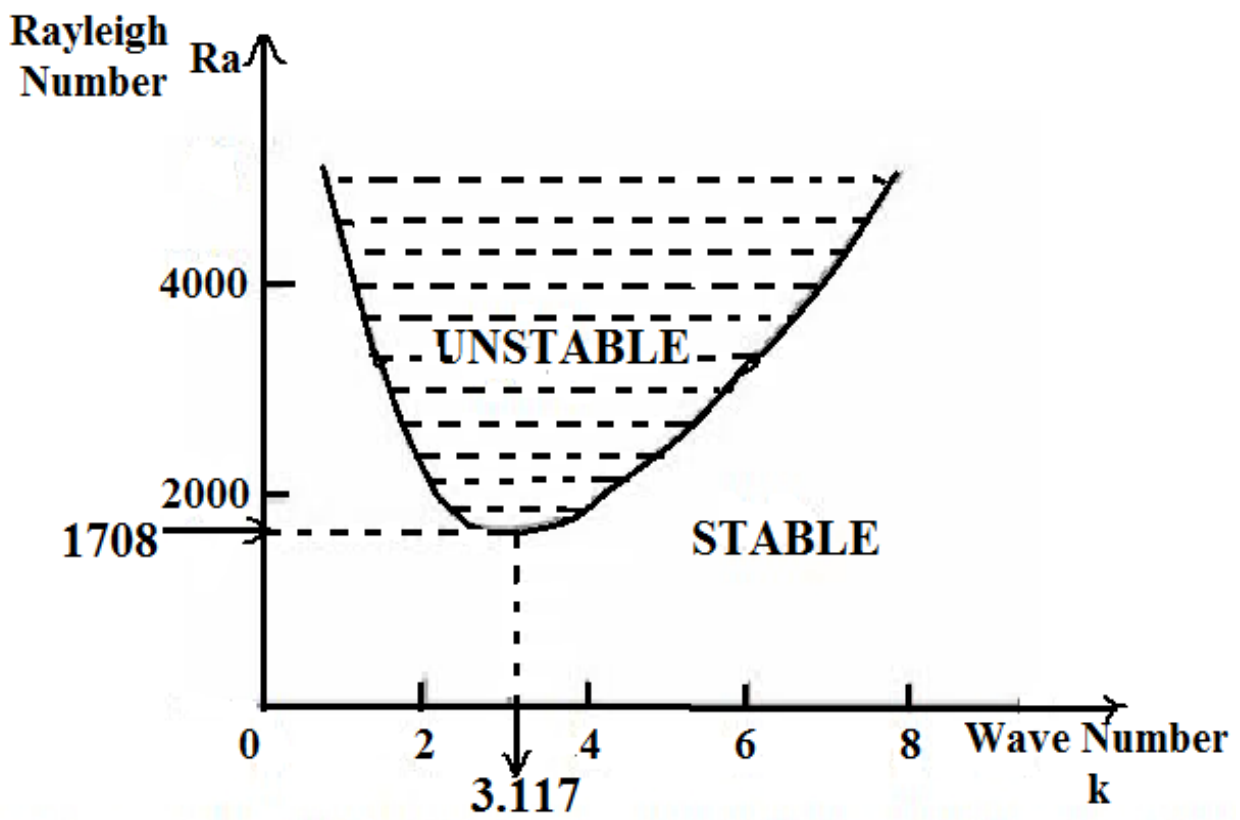

Fig.8 The Instability curve for various Rayleigh numbers

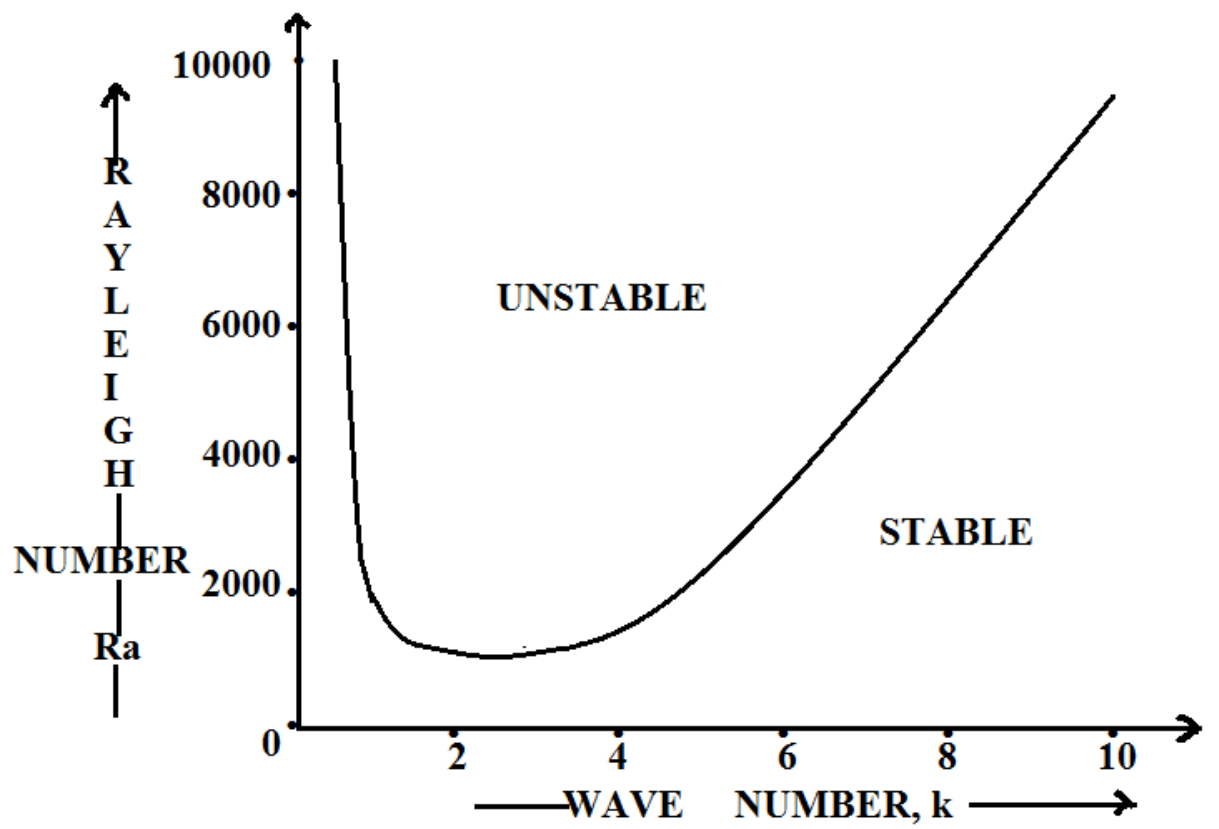

Fig.9 The instability curve obtained by Dr. Lennon O Naraigh [5]

The situation when convection has just started with minimum Rayleigh number, $\mathrm{R}_{\min }$ is shown in Fig.10. The convection is shown by circles which are slightly elliptical in shape decreasing in size outwards from the center. They are the Rayleigh-Benard circles mentioned in literature shown decreasing in size just to match the size of the magma chamber which is shown elliptical in shape.

4.2 Instability of Convection: Instability of convective motion will occur only for Rayleigh numbers of very high values which can disturb the ordered convective flow and finally disrupts the stability of convective motion of gas giving rise to disordered or turbulent flow of gas even if it is contained in a resting closed system.. The types of motion for another two high Rayleigh numbers 2084 and 9215 are shown in Fig.11 and Fig.12 respectively. In the literatures are available computerized pictures of the corresponding figures which are shown in Fig.13 and Fig.14. 
International Advanced Research Journal in Science, Engineering and Technology

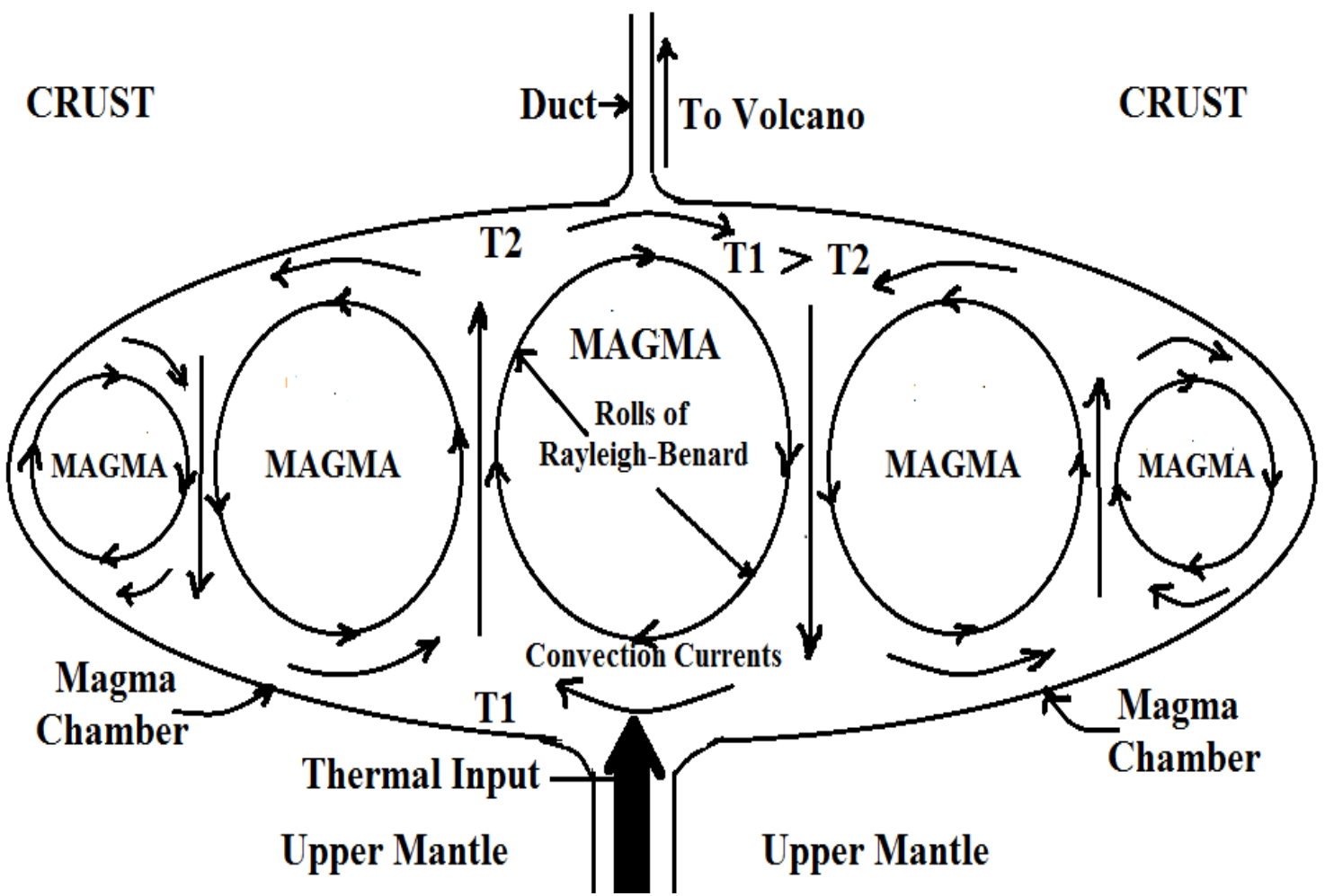

Fig.10 Figure illustrating the start of the Convection for $\mathrm{R}_{\min }=658$ (Drawn by Author: (C) IARJSET)

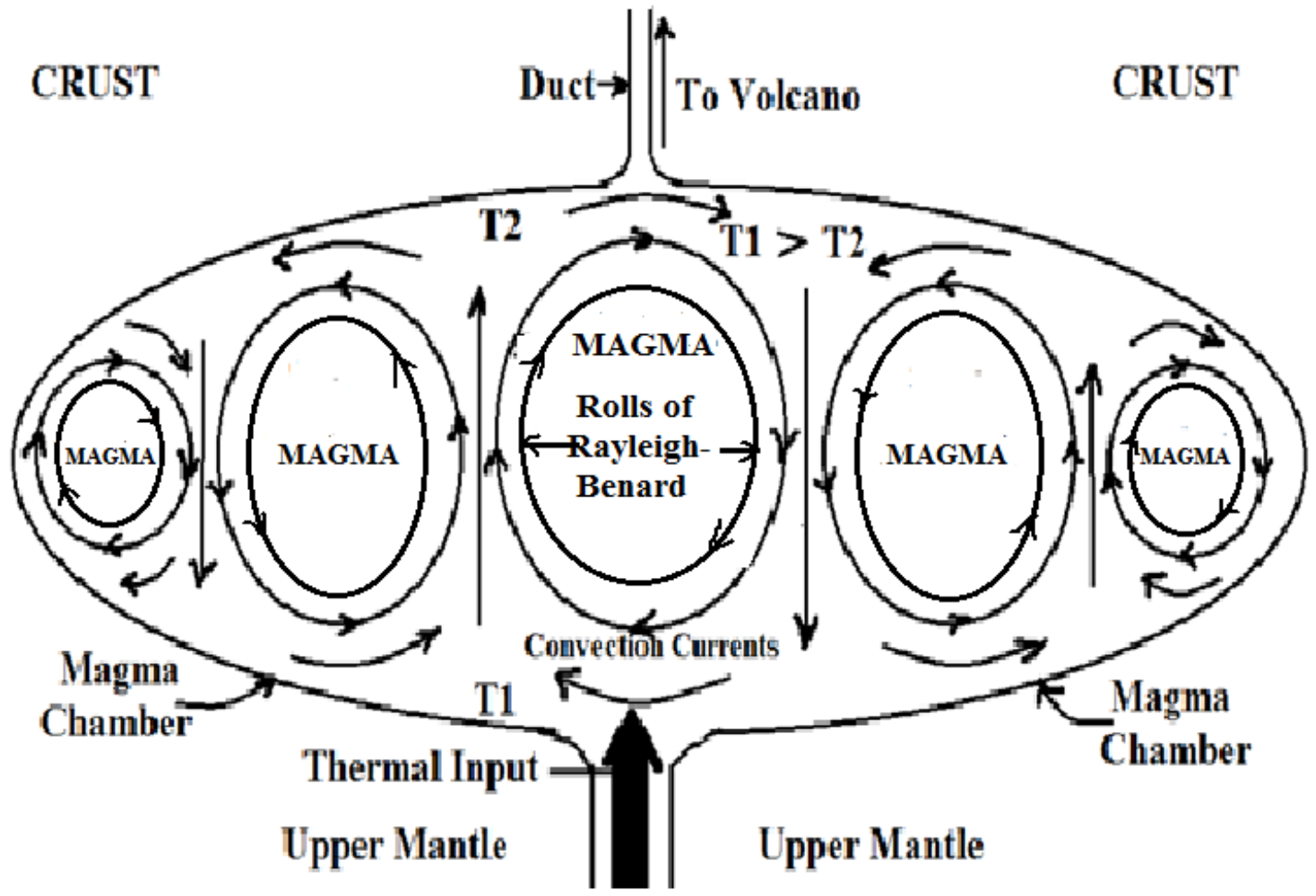

Fig.11 Convection for Rayleigh number 2084 (Figure drawn by Author: @ IARJSET) 


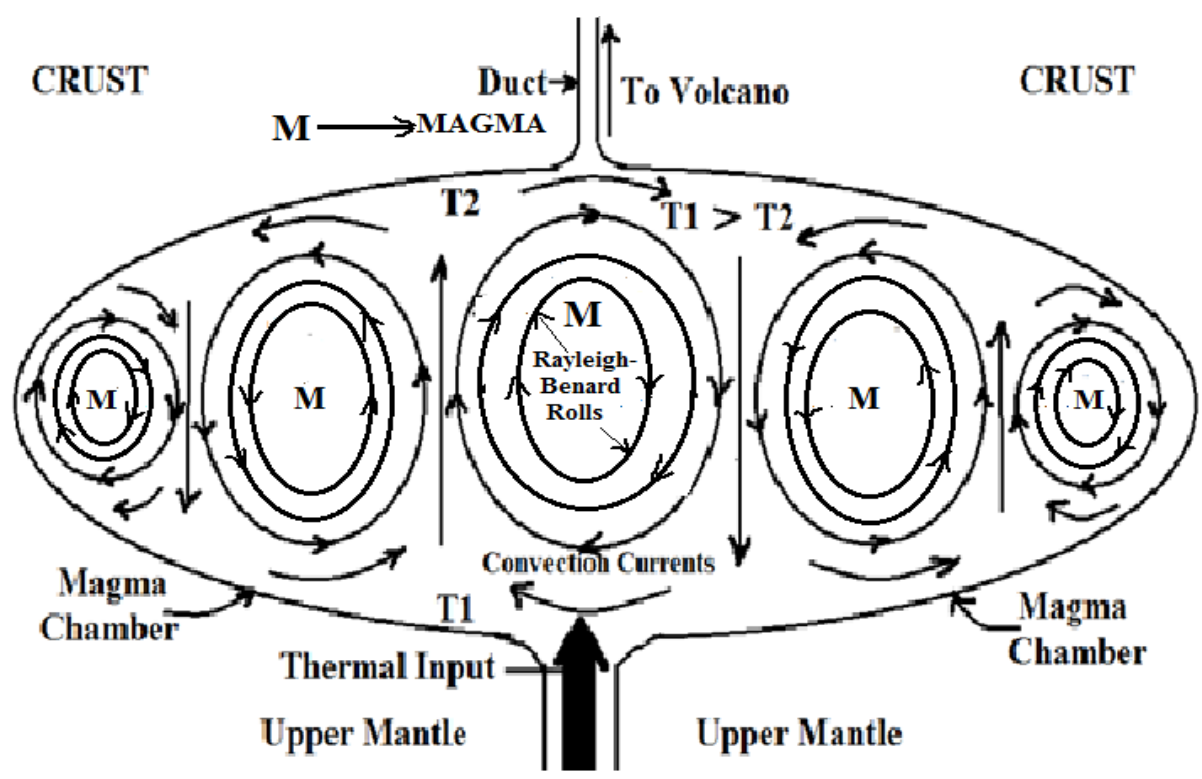

Fig.12 Convection for Rayleigh number 9215 (Figure drawn by Author: @ IARJSET)

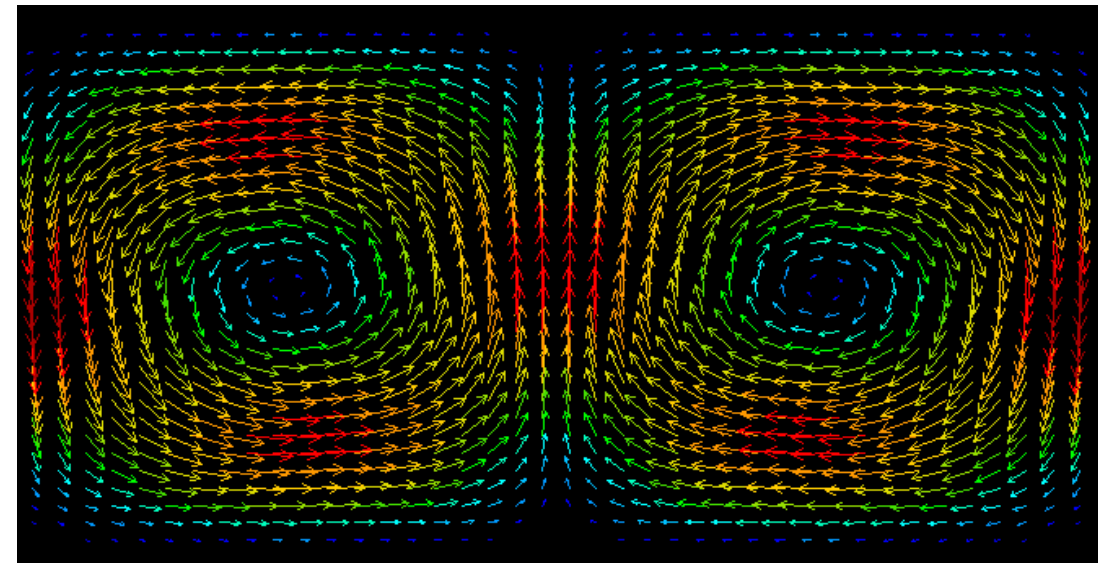

Fig. 13 Computerized picture of convection for Rayleigh number 2084

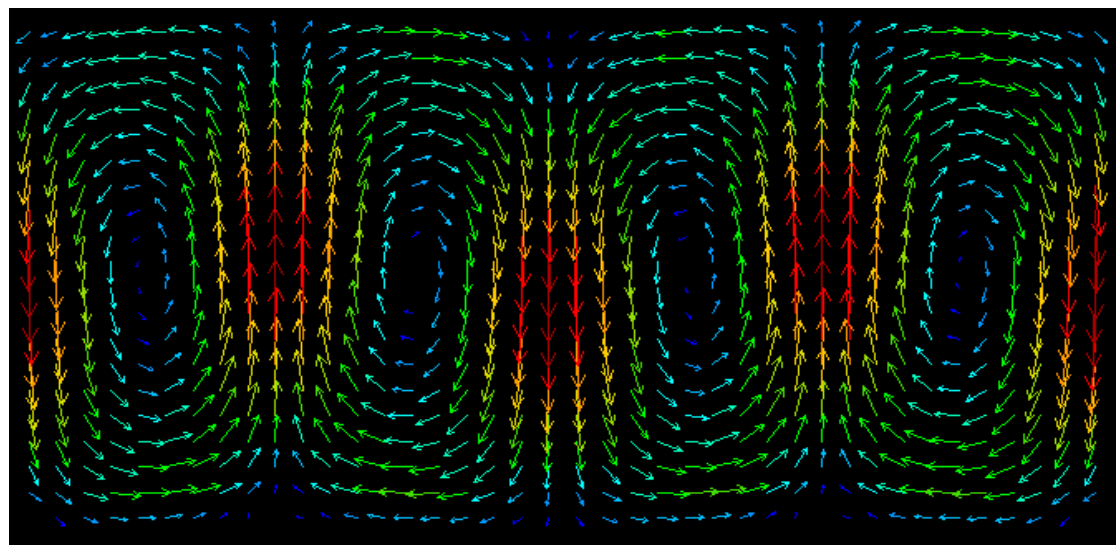

Fig.14 Computerized picture of convection for Rayleigh number 9215

[Note: The free hand diagrams by Author and the computerized pictures shown above might differ and may not have much similarity and comparison. The former is a hand-drawn elliptical figures whereas the latter is a square or rectangular pattern. As taking observation is the profession of a physicist, what is to be observed in the figures is the number of arrows and the complexity of the arrows..] 


\section{International Advanced Research Journal in Science, Engineering and Technology}

Vol. 6, Issue 9, September 2019

4.3 The Turbulent Flow: As convection leading to turbulence is ideal for triggering of eruptions, let us analyze the development of turbulent gas flow. Smirnov [Fig.14, p.99 ] has considered a much higher value of $\mathrm{R}=108 \pi^{4}=10520$ which is some 16 times $R_{\min }$. In this case there can simultaneously develop two different types of convective motion. Fig.15[11] shows two types of convective motion for the Rayleigh number $108 \pi^{4}$ corresponding to the wave number $\mathrm{k}_{1}=\frac{9.4}{\mathrm{~L}}$ for $\mathrm{n}=1$ and $\mathrm{k}_{2}=\frac{4.7}{\mathrm{~L}}$ for $\mathrm{n}=2$. The mixing of the gas flows travelling in opposite directions finally results in a random gas motion or turbulence. The higher the $\mathrm{R}_{a}$ the convection becomes vigorous. In other words, $\mathrm{R}$ of such high value is a measure of convective vigor.

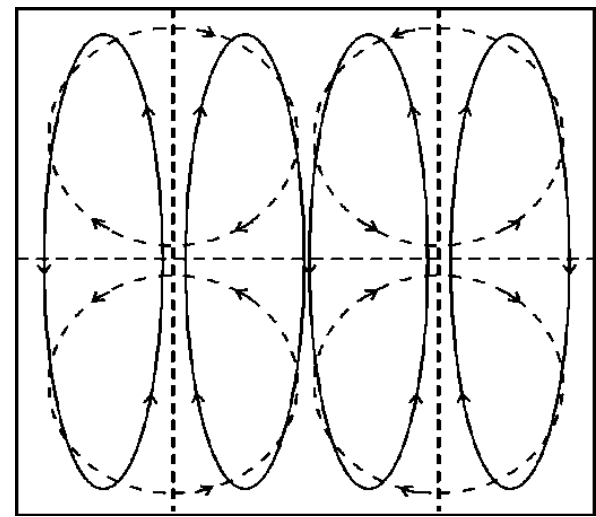

Fig.15 Paths of the gas elements for Rayleigh number, $\mathrm{R}_{a}=108 \pi^{4}=10520$ (Credit: Smirnov [11])

The fact that increasing the Rayleigh number facilitates the convective flow to become turbulent as other wise the system has an ordered convective flow except that a small perturbation somewhere in one of the regions of the gas volume gives rise to another type of flow. At the boundary wall of the region two opposite gas flows meet such that the kinetic energy of motion of the gas flows gets transformed into the thermal energy of the gas. This results in a disordered motion of the gas. The development of turbulence not only changes the character of heat transport but facilitates vigorous eruptions.

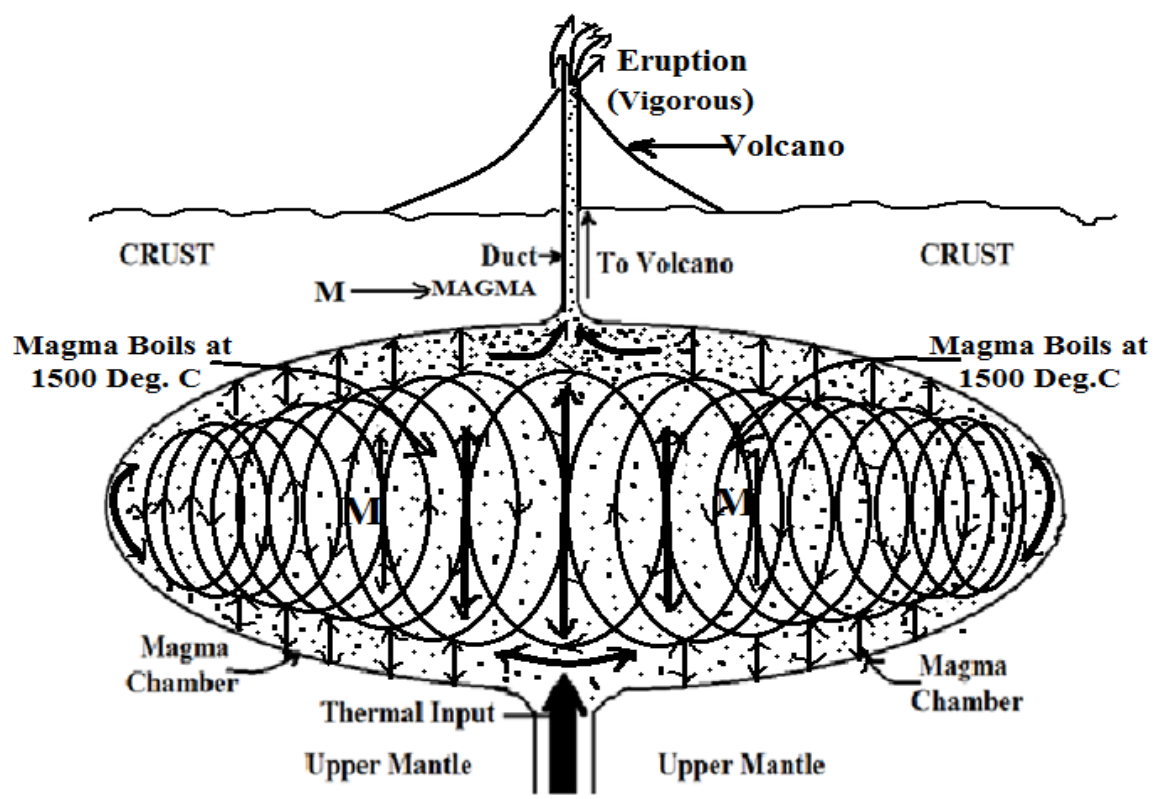

Fig.16 The Turbulence of Magma in the Chamber (Drawn by Author: @ IARJSET)

Coming back to our traditional representation of figures, the situation of magma turbulence can be denoted by a complicated Fig.16 ferocious as it looks each Rayleigh-Benard convection elements overlapping with haphazard arrows meaning thereby that the turbulence has already set in which can initiate an eruption. In fact, I have shown in the figure that a vigorous eruption has already started. 


\section{International Advanced Research Journal in Science, Engineering and Technology}

Vol. 6, Issue 9, September 2019

The Figures 10, 11, 12 and 16 are 3-dimensional. Hence, they are shown elliptical diminishing in size outwards from the center.

The author has shown a very interesting illustration in Fig.17. A caricature of an amateur volcanologist is shown looking at the turbulent magma with wonder (Look at his eyes). He stands somewhere far north of the State of California and looks at the bottom of the Earth may be some 3 or 5 kilometers below the surface so as to locate the magma chamber. Even though there is no volcano in the region between Sacramento and San Jose, I have shown in one of my Papers, Nair V.C.A [8] that the size of the magma chamber of a powerful volcano of Volcano Explosive Index 8 (VEI:8) is as big as that size. The Figure 17 is 3-dimensional and hence the Rayleigh-Benard circles are purposely shown elliptical decreasing in size outward from the center. The entire diagram is drawn free-hand by author and I hope the readers will appreciate the same.

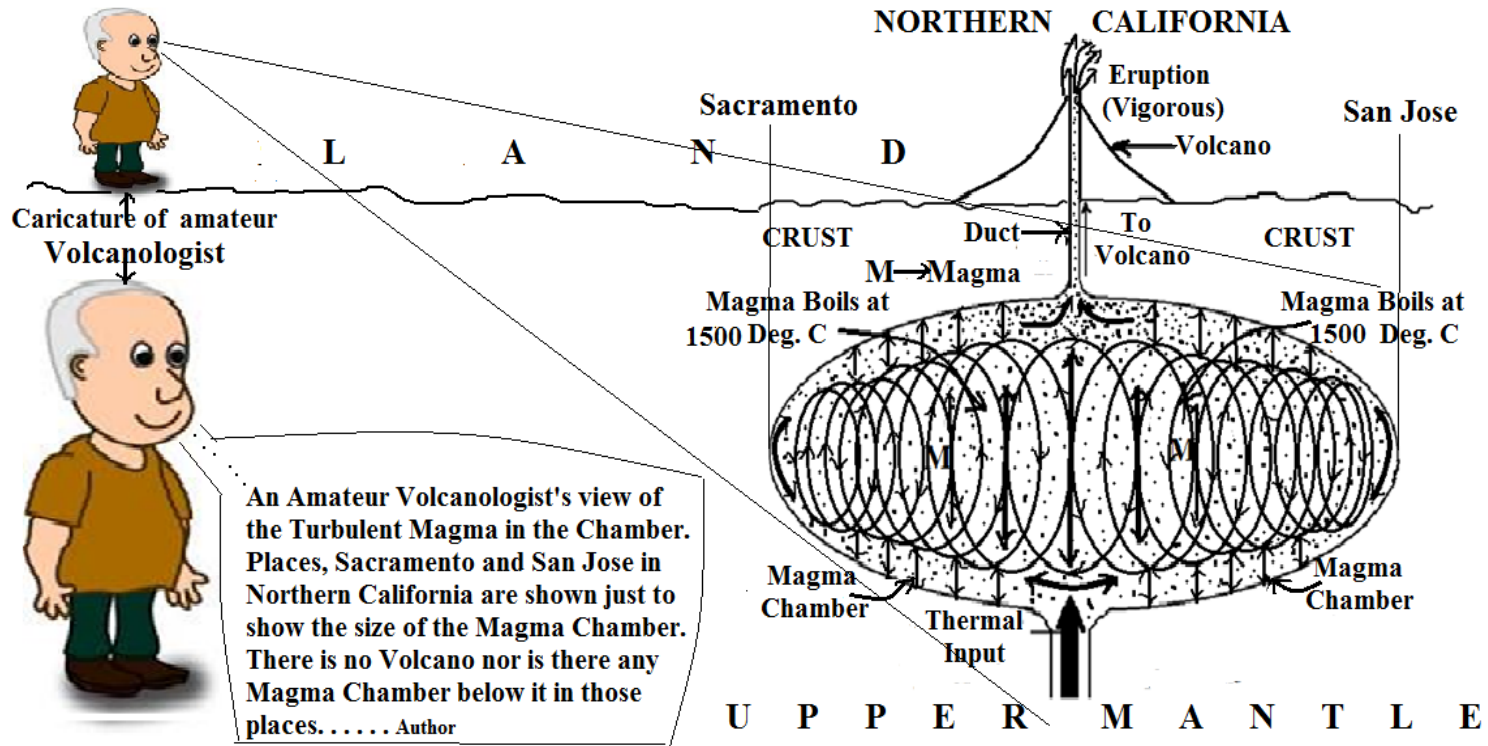

Fig.17 A Volcanologist's view of the Magma Turbulence and the resulting vigorous Eruption' (Picture drawn by Author: () IARJSET)

\section{THE RAYLEIGH NUMBER FOR THE MAGMA IN THE CHAMBER}

5.The equation (9) is given by

$$
\mathbf{R}_{\mathbf{a}}=\left[\frac{\left(\beta \Delta \mathbf{T} \mathbf{c}_{\mathrm{v}} \mathbf{g} \boldsymbol{\rho}^{2} \mathbf{L}^{3}\right)}{\eta \chi}\right]
$$

This formula needs slight modification. The two multiples appearing in the denominator are $\boldsymbol{\eta}$ and $\chi$ where $\boldsymbol{\eta}$ is the usual shear viscosity and the other $\chi$, the Coefficient of Thermal Conductivity. But, what is required as per Guenter Ahlers [3] is the kinematic viscosity, $\boldsymbol{v}$ and the thermometric conductivity more better known as the Thermal Diffusivity, K. Hence we proceed as follows:

$$
\begin{aligned}
\text { Kinematic viscosity, } \boldsymbol{v} & =\frac{\text { Shear Viscosity, } \boldsymbol{\eta}}{\text { Density, } \boldsymbol{\rho}}=\frac{\eta}{\rho} \\
\text { Now, for Thermal Diffusivity, } \mathrm{K} & =\frac{\text { Thermal Conductivity }}{\text { (Specific heat)(Density) }}=\frac{\chi}{\mathbf{c}_{\mathrm{v}} \boldsymbol{\rho}}
\end{aligned}
$$

Now bring $\mathbf{c}_{\mathbf{v}}$ and $\boldsymbol{\rho}^{2}$ [split as ( $\left.\boldsymbol{\rho}\right)(\boldsymbol{\rho})$ ] from the numerator of equation (13) and put them in the denominator so that the equation becomes :

$$
\mathbf{R}_{\mathbf{a}}=\left[\frac{\left(\boldsymbol{\beta} \Delta \mathbf{T} \mathbf{g ~ L}^{3}\right)}{\left(\frac{\eta}{\rho}\right)\left(\frac{\chi}{c_{v}}\right)}\right]=\left[\frac{\left(\beta \Delta \mathbf{T} \mathbf{g ~ L}^{3}\right)}{v \mathbf{K}}\right] .
$$

Let us now find the value of Rayleigh number for magma in the chamber of a standard volcano such as the one having the size of a VE-8 comparable to the distance from Sacramento to San Jose in the state of California, US. There is no question of length or breadth. Let the shape of the chamber be a sphere of diameter $\mathrm{L}$ as per notation chosen by us in the formula. (Fig.18) 


\section{International Advanced Research Journal in Science, Engineering and Technology}

Vol. 6, Issue 9, September 2019

The distance from Sacramento to San Jose is 120 Miles [Google Search] equated to $192 \mathrm{~km}$ and can be approximated as $200 \mathrm{~km}$. Thus, $\mathrm{L}=200 \mathrm{~km}=2 \times \mathbf{1 0}^{\mathbf{5}}$ meter. Thermal diffusivity requires some calculation:

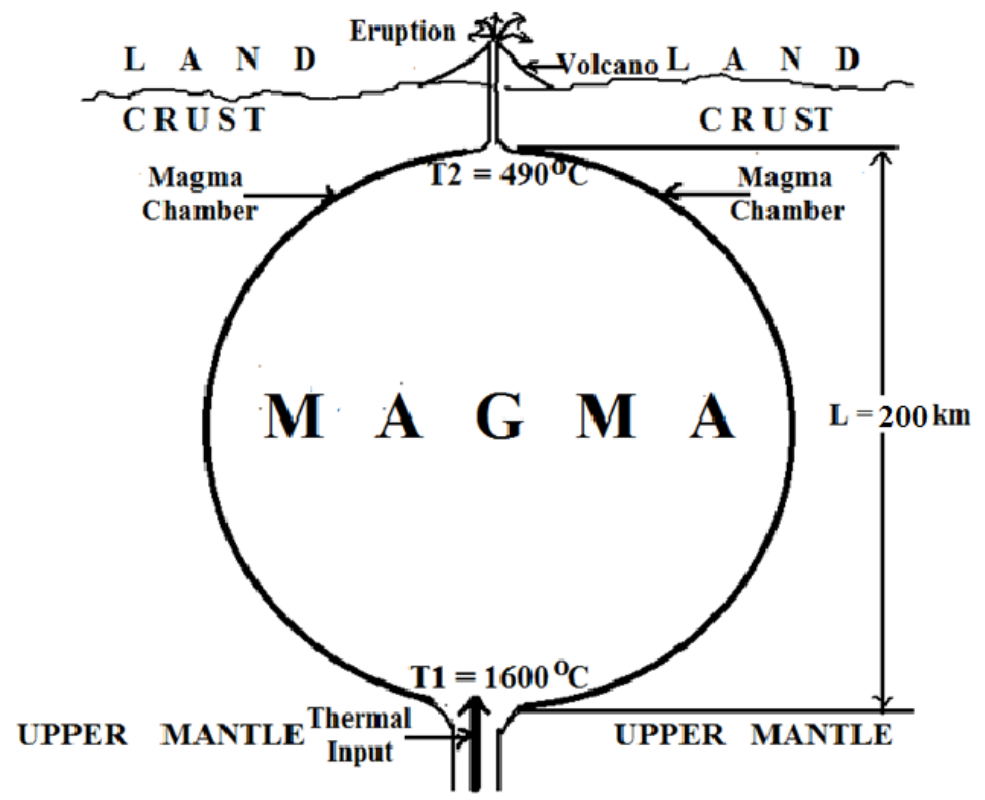

Fig.18 Figure illustrating the values required to work out the Rayleigh Number for Magma in the

Chamber (Fig. drawn by Author: (c) IARJSET)

Thermal diffusivity, $\mathrm{K}=\frac{\text { Thermal Conductivity }}{(\text { Specific heat })(\text { Density })}=\frac{\chi}{\mathbf{c}_{\mathrm{v}} \rho}=\frac{\mathbf{0 . 6}}{(\mathbf{1 4 5 0})(\mathbf{2 6 0 0})}=1.59 \times \mathbf{1 0}^{-\mathbf{7}}$

Now, the choice for value of kinematic viscosity is tricky and complicated. Seth Stein [10] has given an illustrative chart for viscosities of different types of magma (Fig.19). As viscosity increases with decrease of temperature, We can choose a suitable value for $\boldsymbol{v}$ keeping in mind

$1 \mathrm{~Pa} \mathrm{~s}=10$ Poise

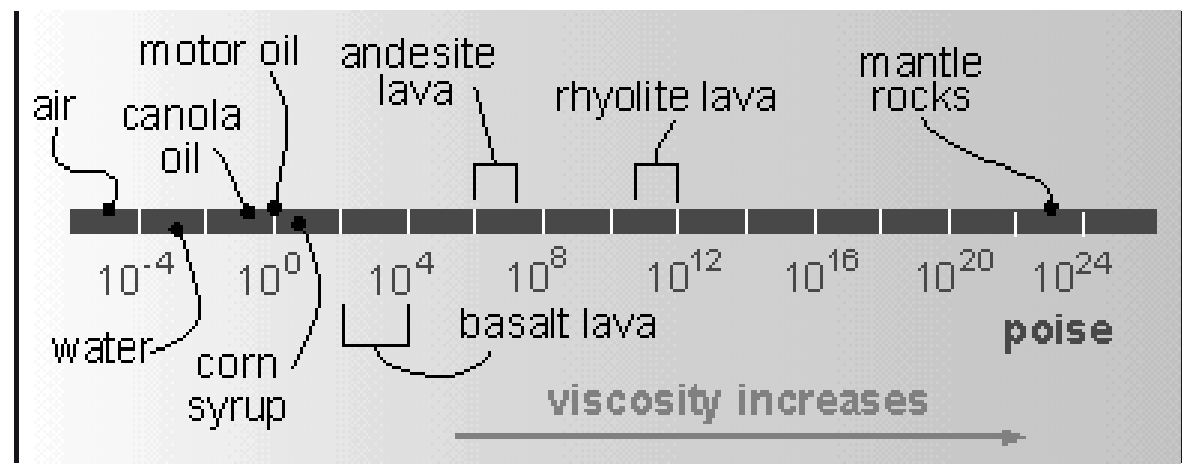

Fig.19 Illustrative Chart for Viscosity of different types of Lava [10]

It is legitimate to choose a value of $\mathbf{1 0}^{\mathbf{1 2}} \mathrm{Pa} \mathrm{s}$ as the value for $\boldsymbol{v}$. Let us write down values for other quantities. Bercovici [2] has mentioned the value of cubical expansion of magma, $\boldsymbol{\beta}$ as $3 \times \mathbf{1 0}^{-\mathbf{5}}$ per degree Celsius. $\Delta \mathbf{T}=\left(\mathbf{T}_{\mathbf{1}}-\mathbf{T}_{\mathbf{2}}\right)=1600^{\circ} \mathrm{C}-490^{\circ} \mathrm{C}=1110^{\circ} \mathrm{C}$. The acceleration due to gravity, $\mathrm{g}=9.8 \frac{\mathbf{m}}{\mathbf{s}^{2}}$ can be approximated to $10 \frac{\mathbf{m}}{\mathbf{s}^{2}}$. The values can now be substituted in the formula for the Rayleigh number:

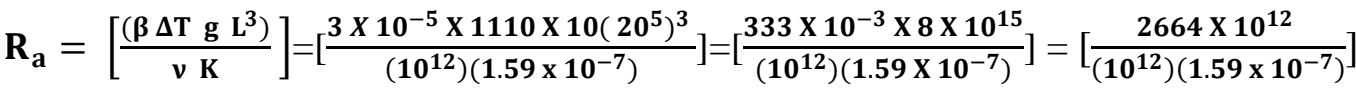

$$
\begin{aligned}
& =1675 \times \mathbf{1 0}^{\mathbf{7}}=1.675 \times \mathbf{1 0}^{\mathbf{1 0}}
\end{aligned}
$$




\section{International Advanced Research Journal in Science, Engineering and Technology}

Vol. 6, Issue 9, September 2019

where we substituted the value $\mathbf{1 0}^{\mathbf{1 2}}$ for the viscosity of Rhyolite lava from the Fig.19. A multiple of 10 or even $100=\mathbf{1 0}^{\mathbf{2}}$ for the value of $\boldsymbol{v}$ is not going to affect much in the value for $\mathbf{R}_{\mathbf{a}}$. It is really a trial and error method. In a lighter vein I would like to mention: "As reasonable assumptions are permitted in Physics, I, however, take this choice as an allowed manipulation".

The question now is whether the value, $1.675 \times \mathbf{1 0}^{\mathbf{1 0}}$.for the Rayleigh number is appropriate with standard values obtained by researchers, This requires a further Review of Literature. Stephen Clark, et.al [13] has shown the range of values for the Rayleigh number to be between $\mathbf{1 0}^{\mathbf{9}}$ and $\mathbf{1 0}^{\mathbf{1 7}}$. Thus our value, $1.675 \times \mathbf{1 0}^{\mathbf{1 0}}$ is reasonably correct.

Shingo Takeuchi [12] has something different to say: He says: Pre-eruptive magma viscosity, an important measure of magma eruptibility Shingo Takeuchil Received 20 January 2011; revised 23 June 2011; accepted 11 July 2011; published 5 October 2011. Using a compilation of melt compositions, melt water contents, temperatures, and phenolcryst contents, the pre eruptive viscosities under magma reservoir conditions are calculated for 83 erupted magmas. The basaltic-to-rhyolitic magmas have pre eruptive viscosities over the range $\mathbf{1 0}^{\mathbf{1}}$ to $\mathbf{1 0}^{\mathbf{8}} \mathrm{Pa}$.

\section{THE ERUPTION}

6. When the turbulence has set in the magma chamber with very high values of the Rayleigh number as per literature mentioned above, magma fragmentation starts making it of high fluidity. The molten magma being of low density rises above to the surface through the vent. The eruption will continue depending upon the quantity of magma in the chamber facilitated by additional new entry of magma from the upper mantle. An explosive eruption will only take place if the pressure within the magma exceeds the strength of the surrounding rock. These explosive eruptions are driven by the thermal energy stored in the magma. The thermal energy is transferred into kinetic energy of the eruption column through the expansion of gases into growing vesicles (air bubbles)

\section{CONCLUSION}

What we have dealt with in the Paper is an exhaustive treatment on Convection of Magma in the Chamber. It has consumed most of the physical aspects supported by Mathematics which is the language of Physics. Readers may be surprised as to how such large quantity of lava (the cooled magma after eruption) can come out of the chamber and hence from the mantle as if emptying both going against the principle of conservation of mass and energy. But, the fact remains that the radioactive process taking place inside the core of the Earth right from its formation still continues to produce material as otherwise there is no energy balance. Nature including the Earth is a Physicist self-adjusting and compromising a quality very much rare with the humans.

After presenting this exhaustive material, the conclusion arrived at by me is that the entire process is something like an Automobile with an Engine running with an Accelerator, even though there are now-adays some Electric Vehicles without Engine. Well ! Convection of magma in the Chamber is the Engine of Eruption and Instability of Convection is the Accelerator of that Engine. Most of the Figures are drawn freehand by the Author with the copy-right surrendered to the publisher

\section{ACKNOWLEDGEMENT}

1.B.M. Smirnov: My sincere acknowledgement with thanks to Prof. B.M. Smirnov Author of the Classical book, "Introduction to Plasma Physics" from which the basic material (Specially the mathematical part) has been taken. The book is originally in Russian (1975 edition) translated by Oleg Glebov and published by Mir Publishers, Moscow in 1977. Smirnov is a great researcher in Theoretical Physics specially in Plasma Physics with a large number of publications to his credit.

Some of the equations in the book are really hard nut to crack and I would like to compliment the Smirnov by calling him a great Mathematical Physicist. I have a personal copy of the book and for others it is out of stock in the market. 


\title{
International Advanced Research Journal in Science, Engineering and Technology
}

\author{
Vol. 6, Issue 9, September 2019
}

2. V.C.A. Nair: There is nothing like self-acknowledgement. In fact, it should be from readers who has completely read and gone through my Paper and they should acknowledge. As that is not possible, I do their job and acknowledge myself. By virtue of my publishing a large number of Research Papers in Geophysics specially on Volcanoes, I have developed the flare of writing on the topic without much review of literature. That is why readers do not find more references. Most of the diagrams are drawn freehand by author. Readers should enjoy the caricature of the Volcanologist in Fig.17.

\section{REFERENCES}

[1]. BBC News/The Science \& Environment//The Pacific Ring of Fire - Updated on 1 Oct. 2009

[2]. Bercovici David, "Mantle Convection Encyclopedia of Solid Earth Geophysics", p.1-27, 26th Dec.2010

[3]. Guenter Ahlers, Professor of Physics at University of California at Santa Barbara, US

[4]. Hans-Peter Bunge, "Paleo Structure of the Earth"es Mantle: Derivation from Fluid Dynamic Inverse Theory" SIAM News Vol.46, No.10, Dec. 2013.

[5]. Dr. Lennon O Naraigh: School of Mathematics and Statistics, University College, Dublin, Ireland ,-Rayleigh- Benard Convection -Linear Thery, p.1-21; Fig.1, p.15 Neutral Curve for the Rayleigh-Benard problem with eigen solution.

[6]. Matt Rosenberg, Professional Geographer and writer .Updated December 22, 2018]

[7]. Miloš M. JOVANOVIĆ , Dragan S. ŽIVKOVIĆ, and Jelena D. NIKODIJEVIĆ Faculty of Mechanical Engineering, University of Niš, Serbia - Rayleigh-Benard Convection Instability in the Presence of temperature variation at the lower wall; Thermal Science, Year 2012, Vol. 16, Suppl. 2, pp. S281-S294 Year 2012.

[8]. Nair V.C.A. The Turbulence of Vaporized Magma in the Chamber at Eruption is akin to its Behavior as an Ideal Gas, Vol.6, Issue 8 August 2019,International Advanced Journal in Science Engineering and Technology p.1-7

[9]. Nair V.C.A. Mantle Convection and Plate Tectonics: A Primary Cause for Earthquakes, Vol.12, Issue-, March 2016, International Journal of Engineering Research and Development, p. 10-21

[10]. Seth Stein, Professor of Physics at California Institute of Technology, US

[11]. Smirnov B.M., Introduction to Plasma Physics, Mir Publishers, Moscow, Ed.1977, p 87-99.

[12]. Shingo Takeuchi, Researcher of the Chinese Academy of Sciences, Pre-eruptive magma viscosity, an important measure of magma eruptibility published 5 October 2011. Using a compilation of melt compositions, melt water contents, temperatures, and phenolcryst contents, the preeruptive viscosities under magma reservoir conditions are calculated for 83 erupted magmas.

[13]. Stephen Clark, Frank J. Spera and David A. Yuen: Steady state double diffusive convection in magma chamber heated from below: - Magmatic Processes-Physicochemical principles-The Geochemical Society, Special publications No.1, 1987, p.289-305. Table No.2 Important dimensionless numbers, p.293.

[14]. USGS (United States Geological Survey): How many active volcanoes are there on Earth? -Natural Hazards

\section{BIOGRAPHY}

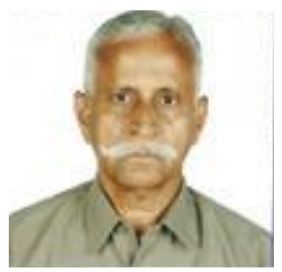

*Dr.(Prof.) V.C.A. Nair (b.15th Aug. 1939) is an Educational Physicist, Counselor, Research Guide and Consultant. He did his Masters in Physics from Mumbai University, India and Ph.D. from Shri. JJT University, Rajasthan also in India He is a Research Guide and distinguished alumni of JJT University. He is also a Chancellor designated Resource Person in the area of Physics in the University. He has to his credit over 4 decades of teaching Applied Physics in eminent Polytechnics in Mumbai and having taught nearly 16,000 students since 1965. He has published a number of research papers in Physics and Geophysics in International and UGC recognized Journals some of which can be seen in the net 'Google Search' when the name of the author or his e-mail is clicked in that style. He is a Life Member of Indian Society for Technical Education which is an all India body. He had been to USA a number of times and visited eminent Universities such as Stanford, Harvard, MIT, 3 Universities of California at Berkeley, Los Angeles and also at Davis ,University of Princeton at New Jersey, Roosevelt University at Chicago, University of Chicago and University of San Francisco. At present Dr. Nair is a Research Guide for Physics at Shri JJT University, Rajasthan-333001, India .He is a registered candidate for the Degree of Doctor of Science (D.Sc) of Madurai Kamaraj University, Tamil Nadu, India.

He is a member of the Editorial Board of this Journal. His Ph.D. Thesis is in Geophysics and he is working on topics such as Tides, Clouds, Global Warming and Climate Change. - Editor.

*nairvca39@gmail.com 